University of Pennsylvania Carey Law School

Penn Law: Legal Scholarship Repository

Faculty Scholarship at Penn Law

6-2003

\title{
The Effect of Abortion Legalization on Sexual Behavior: Evidence from Sexually Transmitted Diseases
}

Jonathan Klick

University of Pennsylvania Carey Law School

Thomas Stratmann

George Mason University

Follow this and additional works at: https://scholarship.law.upenn.edu/faculty_scholarship

Part of the Diseases Commons, Family, Life Course, and Society Commons, Gender and Sexuality Commons, Health Law and Policy Commons, Health Psychology Commons, Law and Gender Commons, Law and Society Commons, Sexuality and the Law Commons, Women's Health Commons, and the Women's Studies Commons

\section{Repository Citation}

Klick, Jonathan and Stratmann, Thomas, "The Effect of Abortion Legalization on Sexual Behavior: Evidence from Sexually Transmitted Diseases" (2003). Faculty Scholarship at Penn Law. 1119. https://scholarship.law.upenn.edu/faculty_scholarship/1119

This Article is brought to you for free and open access by Penn Law: Legal Scholarship Repository. It has been accepted for inclusion in Faculty Scholarship at Penn Law by an authorized administrator of Penn Law: Legal Scholarship Repository. For more information, please contact PennlawIR@law.upenn.edu. 


\title{
The Effect of Abortion Legalization on Sexual Behavior: Evidence from Sexually Transmitted Diseases
}

\author{
Jonathan Klick and Thomas Stratmann
}

\begin{abstract}
Unwanted pregnancy represents a major cost of sexual activity. When abortion was legalized in a number of states in 1969 and 1970 (and nationally in 1973), this cost was reduced. We predict that abortion legalization generated incentives leading to an increase in sexual activity, accompanied by an increase in sexually transmitted diseases (STDs). Using Centers for Disease Control data on the incidence of gonorrhea and syphilis by state, we test the hypothesis that abortion legalization led to an increase in sexually transmitted diseases. We find that gonorrhea and syphilis incidences are significantly and positively correlated with abortion legalization. Further, we find a divergence in STD rates among early legalizing states and late legalizing states starting in 1970 and a subsequent convergence after the Roe $v$. Wade decision, indicating that the relation between STDs and abortion is causal. Abortion legalization accounts for about one-fourth of the average disease incidence.
\end{abstract}

\section{INTRODUCTION}

Scholars often focus on general changes in social attitudes, changing demographics, and changing public health practices when investigating sexual behavior and sexually transmitted diseases (STDs), effectively disregarding the importance of incentives for individual behavior. This

JONATHAN KLICK is the Robert A. Levy Fellow in Law and Liberty, George Mason University School of Law, and Associate Director of the American Enterprise Institute's Liability Project. Thomas stratmann is at the Department of Economics, George Mason University. The authors thank Steve Levitt and John Donohue for comments and access to their data and Dick Ippolito, Ted Joyce, Tyler Cowen, Andrew Goldstein, and workshop participants at George Mason University for helpful comments on this paper. 
focus might stem from the general practice, found in most of the noneconomic literature on sexuality, of attributing sexual decision making to primarily biological and environmental influences. For example, Hardy and Zabin (1991) model adolescent pregnancy as being determined by biological makeup and development, as well as family structure and community characteristics. While these forces are important, they do little to shed light on how changing costs and benefits of sexual activities cause individuals to change their behavior. Analyses of sexual practices relying on this noneconomic approach often offer no better explanation for changes in behavior than attributing them to general changes in social tastes and preferences.

Analysis of these incentive effects with respect to sexual activity can provide valuable insights that have eluded many public health scholars seeking to understand sexual behavior and its attendant health consequences. Sexually transmitted diseases represent epidemics of "enormous health and economic consequence in the United States" (Institute of Medicine 1997, p. 43). Because of this, the medical community has exhibited great interest in trying to understand the physiological and behavioral determinants of STD incidence. While there are hundreds of articles that examine the characteristics of those people most likely to contract STDs, very little research has been done on how changes in the cost of sexual behavior affect STD infections.

For example, in a report discussing the increase of gonorrhea among teenagers during the early 1970s, the Centers for Disease Control (CDC) suggest that the increase occurred partially because "teenagers became more sexually active" (Mascola et al. 1983, p. 29ss). While this is a plausible explanation, it provides little insight into what generated the underlying change in sexual activity that led to the increase in gonorrhea. Without probing more deeply, epidemiological models have little chance of explaining changes in the patterns of STDs. This general point is reflected in Kremer's (1996) work on AIDS. He points out that the general epidemiological assumption that behavior is exogenous to environment can lead to incorrect conclusions about the cause of disease patterns and, consequently, to misguided public health policy decisions.

In this paper, we examine whether abortion laws introduced in the early 1970s had an effect on sexual behavior, as measured by the proxy of STD incidence. We hypothesize that legalizing abortion lowered the cost of sexual activity, leading individuals to engage in more sex, causing an increase in STDs. Specifically, we examine the effect on the incidence of gonorrhea and syphilis. 
Lately, several researchers have examined the ways in which access to abortion might affect social conditions and behavioral decisions. For example, Donohue and Levitt (2001), Lott and Whitley (2001), and Joyce (forthcoming) examine the relationship between abortion legalization and the decrease in crime in the 1990s. Gruber, Levine, and Staiger (1999) find that individuals who have had abortions would have been 40 percent more likely to live in poverty and 50 percent more likely to receive welfare had they instead become single parents. Akerlof, Yellen, and Katz (1996) relate abortion legalization to the decline in shotgun marriages. That abortion legalization had a large social impact is also evidenced in findings that state abortion reforms in 1970 led to a decrease in teen marriage, teen fertility, and teen out-of-wedlock childbearing (Angrist and Evans 1999).

Despite this wave of interest in the effects of abortion legalization, no previous work has examined the public health effects of abortion legalization. We attempt to fill this gap by examining the consequences of abortion legalization with respect to STDs. We use the judicial and legislative decisions to legalize abortion in five states during the period 1969-70 and the national legalization that occurred with the $1973 \mathrm{Su}$ preme Court decision in Roe $v$. Wade as exogenous changes in the cost of sexual activity. Using state-level panel data for the period 1963-80, our difference-in-differences analysis allows us to control for environmental factors and identify a causal abortion effect on STD rates. ${ }^{1}$ We find that much of the change in STD incidence during the 1970s can be attributed to a simple price effect. Abortion legalization accounts for as much as a quarter of the average syphilis and gonorrhea incidence during the period.

To strengthen the claim that this relationship is causal, we exploit the double quasi experiment provided by abortion legalization. That is, we find that STD rates among early legalizing states diverge from the rates in late legalizing states in about 1970, but the rates for gonorrhea subsequently converge when abortion is legalized nationally in 1973.

In Section 2 below, we present a model that predicts that abortion legalization leads to an increase in STDs. Section 3 describes the empirical model and data. We present our results in Section 4 and conclude in Section 5.

1. This use of state-level panel data to identify a causal relationship is similar to that used by Donohue and Levitt (2001) to determine the causal relationship between these abortion law changes and the decrease in crime rates witnessed during the 1990s. 


\section{CONCEPTUAL FRAMEWORK}

We use the standard assumption that individuals consider the costs and benefits of sexual activities before engaging in sexual intercourse (Posner 1992; Levine 2000). Costs include an unplanned pregnancy, and we will focus on this cost in order to develop our key predictions. ${ }^{2}$

There are numerous costs associated with a pregnancy, in addition to the financial costs of giving birth to and raising a child. For example, a pregnancy might lead the mother to forgo educational opportunities and achieve lower benefits in the labor market (Angrist and Evans 1999). Additional costs accrue to mothers who have children from unwanted pregnancies, as these children might be more prone to health problems (Gruber, Levine, and Staiger 1999). Even in the case in which the child is given up for adoption, the mother pays the physical costs of pregnancy and delivery, as well as the emotional costs that might arise when the baby is given to the adopting parents.

As an unplanned pregnancy is one of the costs of sexual activity, the effect of contraception availability is similar to the effect of abortion availability. If contraception is used, the probability of pregnancy decreases and thus the expected costs decline, leading to an increase in the quantity of sex demanded..$^{3,4}$

The availability of abortion lowers the expected cost of sexual intercourse because the pregnancy can be aborted in the event of undesired conception, thus avoiding many of the costs mentioned above. There are, of course, additional costs associated with the abortion, such as the financial cost of the procedure itself, the physical and/or emotional discomfort induced by the abortion, social or familial opprobrium, and the like. However, the availability of abortion unambiguously lowers the expected cost of sexual intercourse for heterosexual couples relative to a situation in which no abortion option is available. ${ }^{5}$

The legalization of abortion, which occurred nationally in the U.S.

2. We derive our predictions assuming heterosexual sexual activities. The implications of relaxing this assumption will be discussed below.

3. One could also think of the use of contraceptives as leading to an increase in the quantity supplied, if both parties to a sexual event are simultaneously producers and consumers.

4. Levine (2000) presents a review of the economic literature on downward-sloping demand curves for sexual activity, as well as empirical results that support the claim that demand curves for sexual activity are downward sloping.

5. We use the term "couple" generically to designate any pair of individuals who engage in sexual activities. 
with the 1973 Supreme Court case of Roe $v$. Wade, further reduces the expected cost of sexual activity relative to a situation in which abortion is available but illegal. Expected costs decrease because abortion legalization reduces the search costs for pregnant women in finding an abortion provider. Further, legalization also reduces the penalties for both receiving and providing abortions, thus increasing the supply of abortions and possibly lowering the monetary price of the procedure. Moreover, legalization is likely to lead to improvements in the safety of the procedure.

Since abortion legalization reduces expected costs of sexual activities, we predict that the legalization leads to an increase in the quantity of sexual activity among heterosexual couples. This is not to say that every women or man will increase sexual activity. For example, some women who would not consider an abortion may not be affected by the decrease in expected costs. ${ }^{6}$ It suffices for our argument that the decrease in expected costs of sexual activities, due to the noted law change, induces a change in behavior for at least some individuals.

Infection rates for STDs are dependent on, among other things, the volume of sexual activity taking place. Since we predict that abortion legalization leads to increased sexual activities, we also predict a positive effect of abortion legalization on STD incidence.

Formally, if utility is a function of the quantity of sexual activity undertaken $(S)$ and a composite good $(X)$, and the cost of sex $(C)$ includes the total expected cost of giving birth to (or alternatively, for the man, bearing responsibility for) an unwanted child, an individual chooses $S$ to maximize total utility, generating the condition

$$
\frac{\partial U(S, X)}{\partial S}=\frac{\partial C}{\partial S} .
$$

Assuming that $U(S, X)$ is concave in $S$ and that the cost of sexual activity is increasing as the quantity increases, ${ }^{7}$ equation (1) predicts that when the cost of sexual activities declines, individuals will increase these

6. However, even for these women, the cost of rejecting sexual activities increases when abortion is legalized (Akerlof, Yellen, and Katz 1996). Thus, these women may increase their sexual activities because the cost of rejecting sexual activities increases, and not because the cost of an unplanned pregnancy decreases.

7. This assumption seems reasonable if an individual's chances of having an unwanted pregnancy increase as the level of sexual activity increases. 
activities. ${ }^{8}$ Essentially, this is an application of the moral hazard concept or, more fundamentally, the concept of downward-sloping demand curves. ${ }^{9}$

In summary, we predict that the decrease in costs due to the legalization of abortion leads to an increase in sexual activity. As the primary way to contract a sexually transmitted disease is by sexual activity, the model predicts that abortion legalization leads to an increase in individuals with sexually transmitted diseases.

\section{EMPIRICAL METHODS}

Abortion legalization provides a natural quasi experiment to determine the effect of abortion availability on STD incidence. Analysis of this natural quasi experiment requires incidence data before and after the legalization period, which occurred between 1969 and 1973. To capitalize on the variation offered by different legalization dates in different states, analysis of this quasi experiment also requires incidence data by state. Comprehensive incidence data by state that fulfill these criteria are available only for gonorrhea and syphilis.

We examine the effect of abortion legalization on both STDs. Syphilis is more difficult to treat than gonorrhea, and the U.S. government and medical community have engaged in rigorous efforts to eliminate syphilis cases. These efforts have included increased screening and an expanded treatment network (Gayle and Counts 2001). These efforts have minimized the importance of syphilis in epidemiological terms, as the average incidence of syphilis is nine cases per 100,000 population over the 1963-2000 period, compared with the 280 cases of gonorrhea per 100,000 population over the same period. In 1999, a total of 6,657

8. A more elaborate model, which generates the same outcome, can be found in Levine and Staiger (2002). In their model, the individual makes decisions sequentially. At the last stage, the individual will have an abortion if the abortion costs are lower than the costs of giving birth. Since the abortion option is available, the individual is less likely to use alternate forms of contraception when engaging in sexual activities.

9. It is also possible to generate this prediction with a simple model of condom use. If we assume that individuals use condoms to prevent conception and to prevent STD infection but that condoms are costly, abortion availability lowers the contraceptive benefits of condoms without changing the STD prevention value of condoms. This implies that once abortion becomes available, individuals will be less likely to use condoms. As does our model, this model predicts an increase in risky sexual activity owing to abortion legalization. 
syphilis cases in the United States were reported, compared with a total of 360,076 gonorrhea cases (Centers for Disease Control 2000).

While, in principle, our key prediction applies to both diseases, there are reasons to suspect that the magnitude of the abortion effect might differ between the two. In this regard, of particular importance is the finding that syphilis incidence is more heavily influenced by homosexual sexual activity than is gonorrhea (Gayle and Counts 2001). Since our model and hypotheses do not apply to homosexual couples (for which unintended pregnancy is not an issue), we expect a smaller relative effect of abortion legalization on syphilis rates than on gonorrhea rates. ${ }^{10}$

We estimate the regression equation

$$
\text { STDRate }_{i t}=\beta A_{i t}+\boldsymbol{X}_{i t} \boldsymbol{\gamma}+\lambda_{i}+v_{t}+\varepsilon_{i t},
$$

where the dependent variable STDRate ${ }_{i t}$ measures the number of new cases diagnosed with either syphilis or gonorrhea per 100,000 individuals in state $i$ during year $t$. The indicator $A_{i t}$ equals one if abortion is legal for state $i$ during year $t$ and zero otherwise. Our model predicts a positive sign on the coefficient $\beta$. The term $\boldsymbol{X}_{i t}$ is a vector of time-varying state characteristics, and $\gamma$ is its vector of coefficients. The term $\lambda_{i}$ is the state effect, $v_{t}$ is the year effect, and $\varepsilon_{i t}$ is the error term.

As with previous work that uses the state legalization of abortion and Roe $v$. Wade as natural quasi experiments when examining state incidences of particular variables, we estimate our empirical model by weighted least squares (Donohue and Levitt 2001). Consistent with previous work, we weight our variables with the state population in all of our regressions. We will also examine the sensitivity of our results when we use an ordinary least square model with unweighted variables.

Equation (2) includes both state and time fixed effects. State effects allow us to control for state-specific characteristics, such as moral norms, that are otherwise difficult to quantify. ${ }^{11}$ Allowing for individual year effects controls for trends that might exist in STD incidence and for nationwide effects such as changes in sexual awareness or changes in guidelines for reporting cases. Moreover, our year indicators capture other variables that influence rates of STDs nationwide, such as condom use and the use of the pill, which was introduced in the 1950s. As long

10. See, for example, Fox et al. (1998) and Hamers et al. (1995).

11. One possibility could be to include moral proxies, such as religious membership, in our regression equations. Comprehensive state data such as these are not available, but Posner (1992) cites a number of articles that suggest that, once economic variables are included, religious affiliation has little effect on abortion rates. 
414 / THE JOURNAL OF LEGAL STUdies / VOLUME 32 (2) / JUNE 2003

Table 1. States Legalizing Abortion

\begin{tabular}{ll}
\hline Year & \multicolumn{1}{c}{ State } \\
\hline 1969 & California \\
1970 & Alaska, Hawaii, New York, Washington \\
1971 & \\
1972 & \\
1973 & Nationwide \\
\hline
\end{tabular}

as the use of these birth control methods does not systematically vary across states and over time, year and state indicators will capture the effects of these methods on STD rates. ${ }^{12}$ In some specifications, we also control for state-specific time trends to check for robustness.

We use Donohue and Levitt's (2001) description of the changes in state abortion laws as our indicator of abortion legalization. While the U.S. Supreme Court effectively legalized abortion nationwide in 1973, a few states had taken this action previously. Specifically, the California Supreme Court legalized abortion in 1969, followed by the legislatures of Alaska, Hawaii, New York, and Washington in 1970. We list these changes in abortion laws in Table 1 . In addition to this legalization, a number of states liberalized their abortion policies before 1973 to allow for legal abortions in cases in which the mother's life was in danger. ${ }^{13}$ We focus on the former cases since they represent a clear-cut reduction in the cost of sexual activity.

12. We do not examine the effect of the use of contraceptives such as birth control pills or condoms, since, for most of the period under study, these data are available only at the national level and not at the state level. Given these data limitations and since we use year indicators in our specification, it would be impossible to identify precisely the effects of this contraceptive use. However, we do examine changes in laws concerning the availability of the pill for minors.

13. Joyce (forthcoming) includes the District of Columbia as an early legalizer since the District of Columbia statute that limited abortion to cases in which the mother's life was in danger was declared to be unconstitutionally vague in the 1969 case of U.S. $v$. Vuitch (305 F. Supp. 1032 [November 10, 1969]). However, the Supreme Court reversed this ruling in 1971 (U.S. v. Vuitch, 91 S. Ct. 1294 [April 21, 1971]), declaring that the statute was constitutional. The Court's interpretation of the statute, however, put the burden of proof on the prosecution to show that the mother's life was not in danger. This creates some ambiguity in determining what the effective status of the District of Columbia law was prior to Roe $v$. Wade. Joyce demonstrates that pre-Roe abortion rates in the District of Columbia were higher than the rates in either New York or California, which suggests that the District of Columbia was a de facto legalizer. The results presented in our tables were estimated assuming that the District of Columbia did not legalize. Our results, however, remain basically unchanged regardless of whether we code the District of Columbia as an early legalizer or not. 
Using legalization as an independent variable (as opposed to number of abortions performed, for example) is attractive if the change in abortion laws is an exogenous shock. This assumption is reasonable, since it seems difficult to argue that the timing of the legal decisions was endogenous to STD incidence (or to sexual activity, which is the underlying mechanism that generates STDs). ${ }^{14}$ Thus, we assume that no unobserved variables simultaneously cause changes of the abortion laws and changes in state STD rates. If the assumption is correct, legalization is a natural quasi experiment that caused an exogenous decrease in the cost of sexual activity.

We estimate equation (2) for the 1963-80 time period. We chose this time period because state STD data are available only from 1963 onward. As a test for the robustness of our results, we will also examine the period between 1963 and 1975. Examining the shorter time period allows us to determine whether the hypothesized change in behavior occurred rapidly or slowly over time.

As another check for the robustness of our results, we will estimate separate regression equations for males and females and test for the equality of the abortion law coefficient in both equations. This will allow us to determine whether our results are driven by one subgroup of the population or whether the change in relative prices of sexual activities, caused by changes in abortion laws, acted uniformly on males and females. If the coefficients on the abortion legalization indicators for males and females are of equal size, the hypothesis is supported that males and females respond equally in terms of changing their sexual activity in response to changes in its cost.

The list of our control variables in the $X$ vector in equation (2) includes per capita income. The predicted relationship between STD incidence and income is ambiguous. The medical literature suggests that STD infections are concentrated among the poor. However, if sexual activity is a normal good, we predict a positive relationship between incidence and income. ${ }^{15}$ Moreover, STD rates might increase with incomes if there is an implicit price involved in securing sexual activity.

14. This assumption of exogeneity is consistent with previous empirical work on the effects of abortion legalization, such as Donohue and Levitt (2001).

15. Work by Turner et al. (2002) indicates that underdiagnosis among the young is a large problem, especially among black women. Their research suggests that undiagnosed infections might equal the number of diagnosed infections. Fortenberry (1997) reports that, for women, the lag between the time when symptoms of STDs are first recognized and the time when medical care is sought is greater for those with lower household incomes. Each of these findings suggests a "diagnosis" effect, which might be related to income. 
We also include per capita transfer payments in our list of covariates. ${ }^{16}$ Inclusion of this variable is motivated by evidence that transfer payments induce individuals to be less concerned about becoming pregnant since transfer payments often increase with the addition of a child (Moffitt 1998). We also examine the effect of per capita medical transfer payments. The expected effect of medical transfer payments is ambiguous. These payments might lower the cost of STD treatment, which should limit the amount of infection taking place in a given area; however, higher medical transfer payments might allow for more rigorous screening, reducing the amount of underdiagnoses. Thus, areas with more accurate diagnoses might report more STD cases than states with missed diagnoses. Each of these variables might be endogenously determined.

The medical literature suggests that young people are more likely than older people to contract an STD (Fox et al. 1998). ${ }^{17}$ We therefore include demographic variables such as the fraction of the state population between the ages of 15 and 34. Since the CDC reports that blacks account for a large proportion of STD cases (Centers for Disease Control 2000), we include the percentage of the population that is black as one of our control variables. ${ }^{18}$

Further, we include the percentage of the population with a secondary education in our regressions because educated individuals may be more knowledgeable about the fact that sexual activities have the risk of transmitting a sexual disease. ${ }^{19}$ However, more highly educated individuals might face a lower search cost, leading to more sexual activities and related STDs. Education rates could also be endogenously determined.

We also include per capita alcohol consumption in some of our regressions, since there is evidence that alcohol consumption is highly correlated with STD incidence (Centers for Disease Control 2000; Shrier et al. 2001). ${ }^{20}$ This covariate might be problematic though, as alcohol consumption and STD incidence could be simultaneously determined.

In addition, we include an indicator variable for states that make

16. Transfer payments represent all payments from federal and state government agencies to individuals.

17. The age data for intercensus periods are linearly interpolated. Although a smaller age range might be more appropriate to use, the range 15-34 is the only one that can be consistently calculated given changes in census reporting procedures over the period from 1963 to 1980 .

18. For intercensus years, we linearly interpolated the race variable.

19. For intercensus years, we linearly interpolated the education variable.

20. Alcohol consumption data for 1963-69 are linearly extrapolated. 
divorce easier through no-fault divorce rules. A few states changed their rules about the grounds necessary for divorce during the same time period that abortion laws were changing. In order to avoid conflating the two changes, we control for changing state divorce rules. Easier divorce rules will generate more divorces, which could lead to less monogamy and an accordingly higher level of risky sexual behavior. We report the means and standard deviations of our data in Table 2.

\section{RESULTS}

The results for gonorrhea are reported in Table 3, and the results for syphilis are reported in Table 4. In each table, we present four sets of estimates for two time periods, 1963-80 and 1963-75. In each set of the estimates, the first column and its corresponding regression include only the abortion legalization indicator, ${ }^{21}$ the second column includes all covariates, the third column excludes the potentially endogenous regressors (education, alcohol consumption, transfer payments, and medical payments), and the last column adds a state-specific time trend. ${ }^{22}$

The legalization coefficient is positive and statistically significant in all specifications of the gonorrhea regressions (Table 3). For the 1963-80 period, the marginal effect of the law change is estimated to be between 53 and 82 extra cases of gonorrhea per 100,000 people. This represents an increase of between 16 and 25 percent, relative to the average state

21. All of our primary results are robust to using a measure of the number of abortions as an indicator of the cost of obtaining an abortion instead of the legalization indicator. We do not report those results because of concerns that using that measure would induce a simultaneity bias and that these data are a poor indicator of the true abortion rate, since data on illegal abortions are generally unavailable.

22. Prior to estimating equation (2), we compared the STD means of abortion-allowing states and abortion-prohibiting states for the entire time period (that is, controlling for no covariates, year effects, or state effects) in a weighted least squares regression. We found that the mean gonorrhea incidence for state periods in which abortion was legal was higher by 77 cases per 100,000 population, which represents a 35 percent increase over the average in state periods in which abortion was illegal. For syphilis incidence, the mean for periods in which abortion was allowed was higher by .1 cases per 100,000 population, which represents an increase of 1 percent over the weighted average incidence during periods in which abortion was illegal. Thus, our hypothesis finds support in a simple comparison of STD means of before and after abortion legalization. 
Table 2. Summary Statistics

\begin{tabular}{|c|c|c|c|c|}
\hline Variable & Description & Mean & SD & Source \\
\hline Gonorrhea Incidence & Gonorrhea cases per 100,000 population & 325.05 & 320.07 & CDC \\
\hline Female Gonorrhea Incidence & Gonorrhea cases per 100,000 women & 235.45 & 213.54 & $\mathrm{CDC}$ \\
\hline Male Gonorrhea Incidence & Gonorrhea cases per 100,000 men & 420.52 & 469.85 & CDC \\
\hline Syphilis Incidence & Syphilis cases per 100,000 population & 9.34 & 13.05 & $\mathrm{CDC}$ \\
\hline Female Syphilis Incidence & Syphilis cases per 100,000 women & 6.33 & 9.03 & CDC \\
\hline Male Syphilis Incidence & Syphilis cases per 100,000 men & 12.55 & 18.23 & CDC \\
\hline Abortion Legal & Abortion indicator $=1$ if abortion is legal & 46 & .50 & Donohue and Levitt (2001) \\
\hline Early Legalizer Before Roe & Indicator $=1$ if state has legalized and year before 1973 & .02 & .13 & Levine et al. (1999) \\
\hline Early Legalizer After Roe & Indicator $=1$ if state is early legalizer and year after 1972 & .04 & .20 & Levine et al. (1999) \\
\hline Pill Age & $\begin{array}{l}\text { Earliest legal age to obtain contraceptive services without } \\
\text { parental consent }\end{array}$ & 18.72 & 2.54 & Goldin and Katz (2002) \\
\hline Secondary Education & $\begin{array}{l}\text { Percentage of the population with secondary schooling } \\
\text { (intercensus years are linearly interpolated) }\end{array}$ & 55.49 & 10.31 & U.S. census \\
\hline Personal Income & Per capita personal income adjusted by CPI-W ${ }^{a}$ & $10,352.00$ & $2,210.00$ & BEA, BLS \\
\hline Transfer Payments & Per capita transfer payments adjusted by CPI-W & .92 & .35 & BEA, BLS \\
\hline Medical Transfers & Per capita medical transfer payments adjusted by CPI-W & .07 & .06 & BEA, BLS \\
\hline Population 15-34 & $\begin{array}{l}\text { Percentage of the state population aged 15-34 (1963-69 are } \\
\text { linearly interpolated) }\end{array}$ & .31 & .03 & U.S. census \\
\hline Alcohol Consumption & $\begin{array}{l}\text { Per capita ethanol consumption (gallons); 1963-69 are linearly } \\
\text { interpolated }\end{array}$ & 2.54 & 1.00 & $\mathrm{NIH}$ \\
\hline Black Population & $\begin{array}{l}\text { Percentage of the state population that is black (intercensus years } \\
\text { are linearly interpolated) }\end{array}$ & .10 & .12 & U.S. census \\
\hline No-Fault Divorce & No-fault divorce indicator $=1$ if allowed by the state & .34 & .47 & Edlund and Pande (2002) \\
\hline
\end{tabular}

Sources. Data from the Centers for Disease Control (CDC) are from the CDC STD database. U.S. census data are from U.S. Census Bureau (1963-80). Data from the Bureau of Economic Analysis (BEA) are from http://www.bea.doc.gov/bea/regional/spi/. Bureau of Labor Statistics (BLS) data are from http://www.bls.gov/cpi/home.htm. National Insitutes of Health (NIH) data are from http://www.niaaa.nih.gov/databases/ comsum03.htm.

${ }^{a} \mathrm{CPI}-\mathrm{W}=$ Consumer Price Index for Urban Wage Earners and Clerical Workers. 
Table 3. Panel Estimation Relating Abortion Legalization to Gonorrhea Incidence

Table 3.

\begin{tabular}{|c|c|c|c|c|c|c|c|c|}
\hline & \multicolumn{4}{|c|}{$1963-80$} & \multicolumn{4}{|c|}{$1963-75$} \\
\hline & $(1)$ & $(2)$ & (3) & (4) & (1) & (2) & (3) & (4) \\
\hline Abortion Legal & $\begin{array}{c}57.71 \\
(14.35)\end{array}$ & $\begin{array}{c}81.71 \\
(13.12)\end{array}$ & $\begin{array}{l}53.17 \\
(13.15)\end{array}$ & $\begin{array}{l}54.81 \\
(8.84)\end{array}$ & $\begin{array}{c}55.90 \\
(13.89)\end{array}$ & $\begin{array}{c}72.97 \\
(13.23)\end{array}$ & $\begin{array}{c}58.76 \\
(13.26)\end{array}$ & $\begin{array}{c}65.05 \\
(9.18)\end{array}$ \\
\hline Secondary Education & $\ldots$ & $\begin{array}{r}-24.93 \\
(3.79)\end{array}$ & $\cdots$ & $\cdots$ & $\cdots$ & $\begin{array}{r}-33.56 \\
(5.55)\end{array}$ & $\cdots$ & $\cdots$ \\
\hline Personal Income & $\ldots$ & $\begin{array}{l}.06 \\
(.01)\end{array}$ & $\begin{array}{l}.07 \\
(.01)\end{array}$ & $\begin{array}{l}.03 \\
(.01)\end{array}$ & $\cdots$ & $\begin{array}{l}.05 \\
(.01)\end{array}$ & $\begin{array}{l}.06 \\
(.01)\end{array}$ & $\begin{array}{l}.01 \\
(.01)\end{array}$ \\
\hline Transfer Payments & $\ldots$ & $\begin{array}{c}-23.52 \\
(42.65)\end{array}$ & $\ldots$ & $\cdots$ & $\cdots$ & $\begin{array}{c}-13.53 \\
(61.06)\end{array}$ & $\cdots$ & $\cdots$ \\
\hline Medical Transfers & $\ldots$ & $\begin{array}{c}-101.18 \\
(121.38)\end{array}$ & . & $\ldots$ & $\cdots$ & $\begin{array}{l}-29.68 \\
(150.38)\end{array}$ & $\ldots$ & . \\
\hline Population $15-34$ & $\ldots$ & $\begin{array}{r}-5,888.45 \\
(618.54)\end{array}$ & $\begin{array}{r}-4,822.27 \\
(624.31)\end{array}$ & $\begin{array}{c}-527.59 \\
(833.75)\end{array}$ & $\ldots$ & $\begin{array}{r}-3,181.77 \\
(840.91)\end{array}$ & $\begin{array}{r}-2,237.95 \\
(848.99)\end{array}$ & $\begin{array}{c}-1,844.47 \\
(1,057.79)\end{array}$ \\
\hline Alcohol Consumption & . & $\begin{array}{c}84.48 \\
(12.34)\end{array}$ & & $\ldots$ & $\ldots$ & $\begin{array}{c}72.92 \\
(14.22)\end{array}$ & $\cdots$ & $\cdots$ \\
\hline Black Population & . . & $\begin{array}{c}1,411.92 \\
(394.89)\end{array}$ & $\begin{array}{c}-200.74 \\
(339.93)\end{array}$ & $\begin{array}{c}-702.31 \\
(579.26)\end{array}$ & $\ldots$ & $\begin{array}{c}164.01 \\
(508.82)\end{array}$ & $\begin{array}{r}-1,414.94 \\
(425.41)\end{array}$ & $\begin{array}{c}310.39 \\
(886.83)\end{array}$ \\
\hline No-Fault Divorce & $\ldots$ & $\begin{array}{l}20.50 \\
(8.51)\end{array}$ & $\begin{array}{l}40.67 \\
(8.61)\end{array}$ & $\begin{array}{l}23.76 \\
(8.48)\end{array}$ & $\cdots$ & $\begin{array}{l}15.53 \\
(9.55)\end{array}$ & $\begin{array}{l}34.83 \\
(9.63)\end{array}$ & $\begin{array}{c}20.05 \\
(9.28)\end{array}$ \\
\hline State trend & No & No & No & Yes & No & No & No & Yes \\
\hline Adjusted $R^{2}$ & .89 & .92 & .91 & .96 & .88 & .91 & .90 & .96 \\
\hline
\end{tabular}

Note. The dependent variable is the number of individuals per 100,000 who are diagnosed with gonorrhea in year $t$ in state $i$. For $1963-80, N=918$; for $1963-75, N=663$. Each regression is estimated with population weights and state and year fixed effects. Standard errors are in parentheses below coefficient estimates. 
Table 4. Panel Estimation Relating Abortion Legalization to Syphilis Incidence

\begin{tabular}{|c|c|c|c|c|c|c|c|c|}
\hline & \multicolumn{4}{|c|}{$1963-80$} & \multicolumn{4}{|c|}{$1963-75$} \\
\hline & (1) & $(2)$ & (3) & (4) & (1) & (2) & (3) & (4) \\
\hline Abortion Legal & $\begin{array}{l}1.01 \\
(.80)\end{array}$ & $\begin{array}{l}1.66 \\
(.81)\end{array}$ & $\begin{array}{c}.47 \\
(.78)\end{array}$ & $\begin{array}{l}2.30 \\
(.71)\end{array}$ & $\begin{array}{l}2.33 \\
(.81)\end{array}$ & $\begin{array}{l}1.93 \\
(.84)\end{array}$ & $\begin{array}{l}1.73 \\
(.82)\end{array}$ & $\begin{array}{l}2.45 \\
(.74)\end{array}$ \\
\hline Secondary Education & $\cdots$ & $\begin{array}{r}-1.19 \\
(.23)\end{array}$ & $\cdots$ & $\cdots$ & $\cdots$ & $\begin{array}{r}-1.40 \\
(.35)\end{array}$ & $\cdots$ & $\cdots$ \\
\hline Per Capita Income & $\ldots$ & $\begin{array}{c}.001 \\
(.000)\end{array}$ & $\begin{array}{l}.001 \\
(.000)\end{array}$ & $\begin{array}{l}.001 \\
(.001)\end{array}$ & $\cdots$ & $\begin{array}{c}-.000 \\
(.001)\end{array}$ & $\begin{array}{c}-.001 \\
(.001)\end{array}$ & $\begin{array}{r}-.001 \\
(.001)\end{array}$ \\
\hline Transfer Payments & $\cdots$ & $\begin{array}{c}-4.55 \\
(2.63)\end{array}$ & $\cdots$ & $\cdots$ & $\cdots$ & $\begin{array}{c}7.37 \\
(3.89)\end{array}$ & $\cdots$ & $\cdots$ \\
\hline Medical Transfers & $\cdots$ & $\begin{array}{c}7.07 \\
(7.47)\end{array}$ & $\cdots$ & $\cdots$ & $\cdots$ & $\begin{array}{r}-21.19 \\
(9.58)\end{array}$ & $\cdots$ & \\
\hline Population 15-34 & $\cdots$ & $\begin{array}{c}209.74 \\
(38.07)\end{array}$ & $\begin{array}{c}225.21 \\
(37.08)\end{array}$ & $\begin{array}{r}-156.80 \\
(66.52)\end{array}$ & $\cdots$ & $\begin{array}{c}112.41 \\
(53.58)\end{array}$ & $\begin{array}{c}74.43 \\
(52.21)\end{array}$ & $\begin{array}{r}-387.82 \\
(85.53)\end{array}$ \\
\hline Alcohol Consumption & $\cdots$ & $\begin{array}{r}-1.09 \\
(.76)\end{array}$ & $\ldots$ & $\ldots$ & $\cdots$ & $\begin{array}{r}-1.63 \\
(.91)\end{array}$ & $\cdots$ & $\cdots$ \\
\hline Black Population & $\cdots$ & $\begin{array}{c}14.24 \\
(24.31)\end{array}$ & $\begin{array}{c}14.67 \\
(20.19)\end{array}$ & $\begin{array}{c}53.41 \\
(46.22)\end{array}$ & $\cdots$ & $\begin{array}{c}108.04 \\
(32.42)\end{array}$ & $\begin{array}{c}99.44 \\
(26.16)\end{array}$ & $\begin{array}{r}-155.32 \\
(71.71)\end{array}$ \\
\hline No-Fault Divorce & $\ldots$ & $\begin{array}{l}.06 \\
(.52)\end{array}$ & $\begin{array}{l}.04 \\
(.51)\end{array}$ & $\begin{array}{r}-1.60 \\
(.68)\end{array}$ & $\cdots$ & $\begin{array}{c}-.06 \\
(.61)\end{array}$ & $\begin{array}{l}.12 \\
(.59)\end{array}$ & $\begin{array}{r}-1.11 \\
(.75)\end{array}$ \\
\hline State trend & No & No & No & Yes & No & No & No & Yes \\
\hline Adjusted $R^{2}$ & .81 & .83 & .82 & .87 & .83 & .84 & .84 & .88 \\
\hline
\end{tabular}

Note. The dependent variable is the number of individuals per 100,000 who are diagnosed with gonorrhea in year $t$ in state $i$. For $1973-80, N=918$ for $1963-75, N=663$. Each regression is estimated with population weights and state and year fixed effects. Standard errors are in parentheses below coefficient estimates. 
incidence over the time period..$^{23}$

The coefficient on the abortion legalization indicator is also positive and statistically significant in all specifications when we examine the 1963-75 time period. We find that the marginal effect of abortion legalization (between 56 and 73 extra cases per 100,000 population) is comparable in this time period relative to the 1963-80 estimate. This suggests that our findings are not driven by later periods and that the inclusion of later periods actually decreases the marginal effect of abortion legalization.

The estimates for the syphilis regressions in Table 4 show that for the 1963-80 period, the statistical significance of the abortion effect is sensitive to the specification of the regression equation, although we do uniformly find that the coefficients have the hypothesized positive sign. This may reflect the confounding factors for syphilis that we discussed above. When we examine the shorter 1963-75 time period, all abortion legalization coefficients have the hypothesized positive sign and are statistically significant. The results for the $1963-75$ period suggest that abortion legalization leads to an increase of about two cases of syphilis per 100,000 population. This represents about a 20 percent increase over average incidence. ${ }^{24}$

The 1963-75 period may provide the clearest picture of the effect of abortion legalization, because it minimizes the possibility that there are missing variables in our regressions, as some variables may become important in later years but are of no importance in the earlier time period. Moreover, because there is no additional variation in the abortion indicator after 1973, later years shed little light on the effect of abortion

23. We also estimated regressions for all time periods in which we interacted the abortion indicator with a time trend to discern whether this effect grew with time, which would perhaps imply that behavior changed slowly. We did not find such an effect. Specifically, it appears as though behavior changed quickly with abortion legalization, leading to an immediate and relatively constant increase in baseline incidence.

24. The results for gonorrhea incidence are qualitatively similar if an ordinary least squares model is estimated. For syphilis, the significance of the abortion coefficient is sensitive to which covariates are included in the specification. Also, the results for gonorrhea and syphilis were qualitatively similar if we used $\ln$ (incidence) as our dependent variables. The relationship between abortion legalization and incidences of gonorrhea and syphilis is positive in all specifications, although in some of the time periods, the relationship was not statistically significant at the 5 percent level. 
on STD incidence if the change in behavior occurred rapidly, as opposed to gradually over time..$^{25}$

As for our covariates, income is uniformly positively correlated with both diseases during the longer time period, but for the 1963-75 period, the result is negative for syphilis, although it is not statistically significant. In most specifications, the positive correlation is statistically significant. This finding is consistent with the hypothesis that sexual activity is a normal good. ${ }^{26}$

In accord with indications from the medical literature, gonorrhea incidence is positively correlated with alcohol consumption. The relationship is statistically significant and positive in every specification. ${ }^{27}$ Alcohol is negatively related to syphilis incidence, though the coefficient is not statistically significant.

The results for most of our other covariates are sensitive to the time period and STD examined. For example, a coefficient on the fraction of young people in the population is negative in the gonorrhea regressions but positive in many of the syphilis regressions. In both cases, statistical significance depends on the specification.

The relationship between secondary education and STD incidence is sensitive to the specification. This might reflect the theoretical ambiguity of education's effect on STD incidence. That is, while schooling increases general health awareness, more educated individuals may face lower search costs in the market for sex, leading to increased sexual activity.

25. By examining the effects of abortion legalization prior to national legalization in Roe $v$. Wade, we can determine whether the national change in 1973 is driving our results. For both syphilis and gonorrhea, the abortion effect is significantly positive for the period 1963-72.

26. Another explanation might be a diagnosis effect. If wealthier people were more likely to have gonorrhea diagnosed than poorer people, our dependent variable would be measured with error because gonorrhea among the poor goes largely undetected. Since access to health care services, including regular doctor visits, is positively correlated with income, this might be plausible. However, much of the CDC's sample comes from sources other than diagnoses in private medical facilities. Specifically, the CDC's data sources include public clinics, jail STD monitoring projects, the U.S. Army, and the Indian Health Service, whose clientele is likely to represent a relatively high proportion of lower-income individuals (Centers for Disease Control 2000). Thus, it is unlikely that a diagnosis effect is causing the positive correlation between income and STD rates.

27. The alcohol consumption variable measures gallons of per capita consumption of ethanol via beer, wine, and liquor by state. These data are available only beginning in 1970 , so we constructed the alcohol consumption variable for the years 1963-69 both by linear extrapolation and by using the 1970 observation for prior years. The magnitude and significance of the relationship between incidence and alcohol consumption were largely independent of which method was used to extrapolate the alcohol data. 
Table 5. Male-Female Comparison of SUR Results for Gonorrhea Incidence

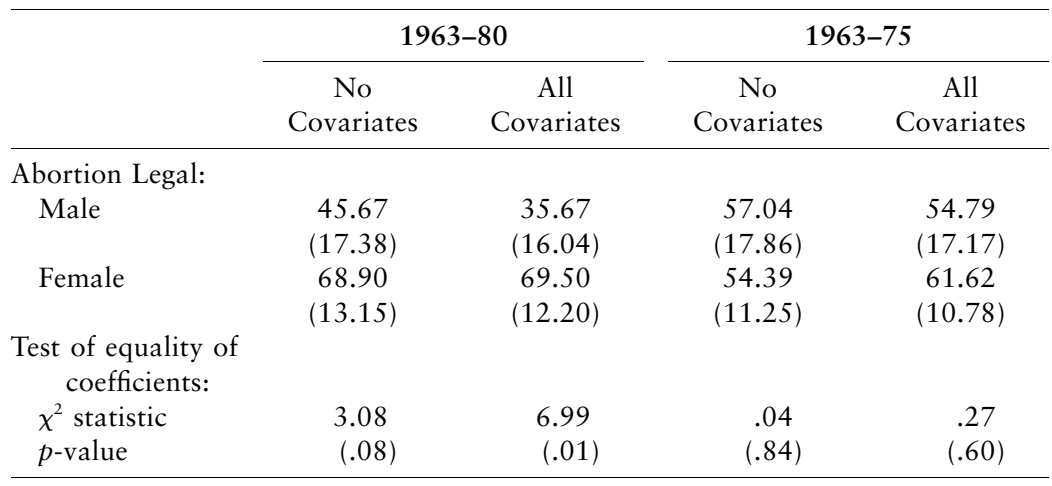

Note. The seemingly unrelated regression (SUR) estimation involves a two-equation system with annual male and female gonorrhea infections per 100,000 of the male and female populations as the dependent variables. All specifications include state and year fixed effects. In each system, the independent variables are identical. (With the exception of the abortion legalization coefficient, we do not report the individual coefficient estimates.) The SUR estimation provides a convenient way to test for the equality of the abortion legalization coefficient in the male and female gonorrhea equations. The covariates in the "All Covariates" regressions are Per Capita Personal Income, Population 15-34, Black Population, and No-Fault Divorce. For 1973-80, $N=918$; for 1963-75, $N=663$. Each regression is estimated with population weights. Standard errors are in parentheses below coefficient estimates.

We noted above that the predictions derived from the changing cost of sexual activities do not apply for homosexual sexual activities. Assuming that homosexual behavior did not change at the same time that abortion laws changed and that heterosexual matching is roughly proportional (that is, it is not the case that a relatively small number of men engage in sexual activity with a large number of women, or vice versa), our model predicts that the relationship between STD incidence and abortion legalization is the same for men and women. In particular, we predict the same marginal effect of legalizing abortion for men and for women.

To test this hypothesis, we examined the data for male and female state gonorrhea and syphilis rates separately. The seemingly unrelated regression (SUR) model allows us to test for the equality of the legalization coefficients in the male STD equation and female STD equation. We report the male and female abortion legalization coefficients from the SUR model for gonorrhea in Table 5. Regardless of the time period or the gender gonorrhea rate examined, all coefficients on abortion legalization are positive and statistically significant. In most specifications, 
424 / THE JOURNAL OF LEGAL STUdies / VOLUME 32 (2) / JUNE 2003

Table 6. Male-Female Comparison of SUR Results for Syphilis Incidence

\begin{tabular}{|c|c|c|c|c|}
\hline & \multicolumn{2}{|c|}{$1963-80$} & \multicolumn{2}{|c|}{$1963-75$} \\
\hline & $\begin{array}{c}\text { No } \\
\text { Covariates }\end{array}$ & $\begin{array}{c}\text { All } \\
\text { Covariates }\end{array}$ & $\begin{array}{c}\text { No } \\
\text { Covariates }\end{array}$ & $\begin{array}{c}\text { All } \\
\text { Covariates }\end{array}$ \\
\hline \multicolumn{5}{|c|}{ Abortion Legal: } \\
\hline Male & $\begin{array}{c}.91 \\
(1.02)\end{array}$ & $\begin{array}{l}.11 \\
(.99)\end{array}$ & $\begin{array}{l}2.99 \\
(.99)\end{array}$ & $\begin{array}{c}2.08 \\
(1.00)\end{array}$ \\
\hline Female & $\begin{array}{l}1.21 \\
(.62)\end{array}$ & $\begin{array}{l}.90 \\
(.60)\end{array}$ & $\begin{array}{l}1.78 \\
(.63)\end{array}$ & $\begin{array}{l}1.47 \\
(.63)\end{array}$ \\
\hline \multicolumn{5}{|c|}{$\begin{array}{c}\text { Test of equality of } \\
\text { coefficients: }\end{array}$} \\
\hline $\begin{array}{l}\chi^{2} \text { statistic } \\
p \text {-value }\end{array}$ & $\begin{array}{l}.21 \\
(.65)\end{array}$ & $\begin{array}{l}1.54 \\
(.22)\end{array}$ & $\begin{array}{l}4.32 \\
(.04)\end{array}$ & $\begin{array}{l}1.09 \\
(.30)\end{array}$ \\
\hline
\end{tabular}

Note. The seemingly unrelated regression (SUR) estimation involves a two-equation system with annual male and female gonorrhea infections per 100,000 of the male and female populations as the dependent variables. All specifications include state and year fixed effects. In each system, the independent variables are identical. (With the exception of the abortion legalization coefficient, we do not report the individual coefficient estimates.) The SUR estimation provides a convenient way to test for the equality of the abortion legalization coefficient in the male and female syphilis equations. The covariates in the "All Covariates" regressions are Per Capita Personal Income, Population 15-34, Black Population, and NoFault Divorce. $N=918$ for 1973-80, and $N=663$ for 1963-75. Each regression is estimated with population weights. Standard errors are in parentheses below coefficient estimates.

the $\chi^{2}$ test for equality of the legalization coefficient in the male and female regressions does not allow us to reject equality at the 5 percent level.

Table 6 reports the legalization coefficients for both genders in the syphilis regressions. We do not reject equality of the coefficients in the male and female regressions in most of the regressions. For some of the specifications limited to analyzing the period $1963-75$, we reject the equality of legalization coefficients. In these cases, the infection rate of men associated with legalization is higher than that of women.

Overall, we therefore find that once we control for other factors that influence STD incidence, besides abortion legalization, the marginal effect of legalization on STD rates is the same for women and for men. Thus, both genders respond equally to a decrease in the cost of sexual activities.

This result is interesting in another respect. Specifically, it rules out the possibility that the abortion legalization effect is merely an artifact of increased diagnoses due to abortion. That is, if abortion providers generally perform STD tests on their patients, we might see a relationship 
between abortion and STD incidence that is related merely to an increased probability of diagnosis rather than a change in sexual activities. Since this form of diagnosis occurs only for women, and if a diagnostic effect were driving our result, we would find a bigger effect for women's incidence than for men's. Since we find no such difference, we can reject this possibility.

As discussed previously, data on the use of contraceptive pills are available only at the national level for most of the period studied. Since we use year fixed effects, it is not possible to net out the effect of possible changes in pill use. Presumably this is not troublesome since birth control pills were available nationally prior the period we examine in this paper. ${ }^{28}$ However, there was variation in state laws regarding the ability of young women to obtain the pill, as detailed in Goldin and Katz (2002). To avoid confounding the effect of these law changes with the abortion effect, we used information on these laws to check for robustness of our results. We constructed a series ${ }^{29}$ on the earliest legal age to obtain contraceptive services without parental consent in each state for the period 1963-78 and included this variable in the regressions presented in Table 7. As the results indicate, including the pill availability measure does not change our primary result. The abortion coefficients for all specifications for both gonorrhea and syphilis remain positive and statistically significant.

The Pill Age variable measures the earliest age at which a woman can receive contraceptive services without parental consent. We expected a negative relationship between this indicator and STD rates, since a lower age implies that young individuals may obtain contraception more easily, lowering the cost of sexual activity to them. The sign and statistical significance of the coefficient was dependent on the specification. ${ }^{30}$

While our results are certainly suggestive of a causal relationship between abortion legalization and increased sexual behavior, as well as

28. The FDA approved the use of norethynodrel as an oral contraceptive for women in 1960 (Goldin and Katz 2002).

29. To construct this series, we used the information in Goldin and Katz's (2002) table 2 , imputing that the legislated earliest ages to obtain contraceptive services for the years 1963-68 were the same as those that existed in 1969. We also assumed that the laws did not change during the period 1975-78. The results are largely unchanged if we reduce the period of analysis so as to require less interpolation.

30. The same qualitative results were estimated when the Pill Age variable took the form of a $(0,1)$ series that indicates whether a 16-year-old (or, alternatively, an 18-yearold) could obtain the pill without parental consent. 
Table 7. Panel Estimation Including the Pill Effect

\begin{tabular}{|c|c|c|c|c|c|c|c|c|}
\hline & \multicolumn{4}{|c|}{ Gonorrhea } & \multicolumn{4}{|c|}{ Syphilis } \\
\hline & (1) & (2) & (3) & (4) & (1) & (2) & (3) & (4) \\
\hline Abortion Legal & $\begin{array}{c}59.48 \\
(14.65)\end{array}$ & $\begin{array}{c}80.16 \\
(13.12)\end{array}$ & $\begin{array}{c}54.78 \\
(13.49)\end{array}$ & $\begin{array}{l}56.46 \\
(9.93)\end{array}$ & $\begin{array}{l}1.77 \\
(.80)\end{array}$ & $\begin{array}{l}1.90 \\
(.80)\end{array}$ & $\begin{array}{l}1.15 \\
(.79)\end{array}$ & $\begin{array}{l}2.08 \\
(.71)\end{array}$ \\
\hline Pill Age & $\begin{array}{c}.04 \\
(1.74)\end{array}$ & $\begin{array}{c}-3.02 \\
(1.59)\end{array}$ & $\begin{array}{c}-1.41 \\
(1.64)\end{array}$ & $\begin{array}{c}.08 \\
(1.49)\end{array}$ & $\begin{array}{l}.33 \\
(.10)\end{array}$ & $\begin{array}{l}.20 \\
(.10)\end{array}$ & $\begin{array}{l}.32 \\
(.10)\end{array}$ & $\begin{array}{c}-.19 \\
(.12)\end{array}$ \\
\hline Secondary Education & $\ldots$ & $\begin{array}{c}-30.94 \\
(4.62)\end{array}$ & . . . & $\ldots$ & $\ldots$ & $\begin{array}{r}-1.39 \\
(.28)\end{array}$ & $\ldots$ & $\ldots$ \\
\hline Per Capita Income & . & $\begin{array}{l}.06 \\
(.01)\end{array}$ & $\begin{array}{l}.08 \\
(.01)\end{array}$ & $\begin{array}{l}.02 \\
(.01)\end{array}$ & $\ldots$ & $\begin{array}{l}.001 \\
(.001)\end{array}$ & $\begin{array}{l}.001 \\
(.001)\end{array}$ & $\begin{array}{l}.000 \\
(.001)\end{array}$ \\
\hline Transfer Payments & . & $\begin{array}{c}-74.16 \\
(48.87)\end{array}$ & $\ldots$ & $\cdots$ & $\cdots$ & $\begin{array}{l}-.30 \\
(2.99)\end{array}$ & $\cdots$ & $\cdots$ \\
\hline Medical Transfers & $\ldots$ & $\begin{array}{c}-.28 \\
(132.47)\end{array}$ & & $\ldots$ & $\ldots$ & $\begin{array}{c}-6.81 \\
(8.12)\end{array}$ & $\ldots$ & $\ldots$ \\
\hline Population 15-34 & $\ldots$ & $\begin{array}{r}-5,368.20 \\
(694.82)\end{array}$ & $\begin{array}{r}-4,190.33 \\
(706.26)\end{array}$ & $\begin{array}{r}-541.40 \\
(914.97)\end{array}$ & $\ldots$ & $\begin{array}{c}203.77 \\
(42.57)\end{array}$ & $\begin{array}{l}186.07 \\
(41.23)\end{array}$ & $\begin{array}{r}-207.33 \\
(72.63)\end{array}$ \\
\hline Alcohol Consumption & . & $\begin{array}{c}87.16 \\
(12.89)\end{array}$ & $\ldots$ & $\ldots$ & $\cdots$ & $\begin{array}{r}-1.33 \\
(.79)\end{array}$ & $\ldots$ & $\ldots$ \\
\hline Black Population & $\ldots$ & $\begin{array}{c}1,047.28 \\
(443.92)\end{array}$ & $\begin{array}{c}-805.94 \\
(379.32)\end{array}$ & $\begin{array}{c}487.34 \\
(651.01)\end{array}$ & $\cdots$ & $\begin{array}{c}67.71 \\
(27.20)\end{array}$ & $\begin{array}{c}63.16 \\
(22.15)\end{array}$ & $\begin{array}{c}12.27 \\
(51.67)\end{array}$ \\
\hline No-Fault Divorce & . & $\begin{array}{c}20.95 \\
(8.90)\end{array}$ & $\begin{array}{c}41.21 \\
(9.08)\end{array}$ & $\begin{array}{c}16.91 \\
(8.71)\end{array}$ & $\cdots$ & $\begin{array}{l}.03 \\
. .55)\end{array}$ & $\begin{array}{l}.01 \\
(.53)\end{array}$ & $\begin{array}{r}-1.30 \\
(.69)\end{array}$ \\
\hline State trend & No & No & No & Yes & No & No & No & Yes \\
\hline Adjusted $R^{2}$ & .88 & .92 & .91 & .96 & .82 & .84 & .83 & .88 \\
\hline
\end{tabular}

Note. The dependent variable is the number of individuals per 100,000 who are diagnosed with the STD in year $t$ in state $i$. $N=816$. All specifications include year and state fixed effects. Standard errors are in parentheses below coefficient estimates. 
increased STD incidence, they do not fully exploit the quasi experiment that legalization provides. Following the research design in Levine et al. (1999), ${ }^{31}$ we can examine what are effectively two separate legalization quasi experiments. That is, states that legalized prior to the Roe $v$. Wade decision can be used as a treatment group, with the nonlegalizing states serving as the control for the first quasi experiment in 1969-70. Second, we can analyze the quasi experiment provided by the Supreme Court's decision in Roe $v$. Wade as a second quasi experiment in which the early legalizing states serve as the control group. If the increase in STD rates is causally related to abortion legalization, we should find a relative increase in STD rates in 1970 among the states that legalize early, but that differential should disappear when other states are forced to legalize in 1973.

Figure 1 shows this 1970 divergence and 1973 convergence quite clearly for gonorrhea. The figure plots the population-weighted average gonorrhea incidence of the early legalizing states against the populationweighted average for the nonlegalizing states. We see a sharp divergence in the two rates in 1970 that subsequently dissipates in 1973. While not quite as clear, Figure 2 suggests a similar pattern of divergence and convergence for syphilis rates. ${ }^{32}$

We can examine this double quasi experiment more rigorously, however, through the use of regression methods. Again following Levine et al. (1999), we create two indicator variables to measure the divergence/ convergence relationship. For the early legalizing states, we create an indicator variable that equals one during the years 1970-72 (1969-72 for California), zero for all other years, and zero for all years in the other states. The second indicator variable equals one for the early legalizing states in the years 1973-80 and zero for all other observations. If the divergence/convergence pattern exists, we should estimate a positive coefficient for the pre-Roe legalization dummy, which captures the fact that those states experienced an increase in STD rates, and we should find no effect from the other dummy since the late legalizing states' STD rates will have converged with those of the early legalizing states.

As shown in Table 8, we find the predicted relationship for gonorrhea

31. Their research examines the effect of abortion legalization on fertility rates. They attribute a statistically significant decrease in U.S. birth rates to the availability of abortion.

32. In the graphical representation, it appears as though the divergence begins just prior to the date of legalization for the early legalizing states. In some sense, since the graphs represent only means, some of the early divergence could be due to the effects of the confounding factors we control for in our regressions. 


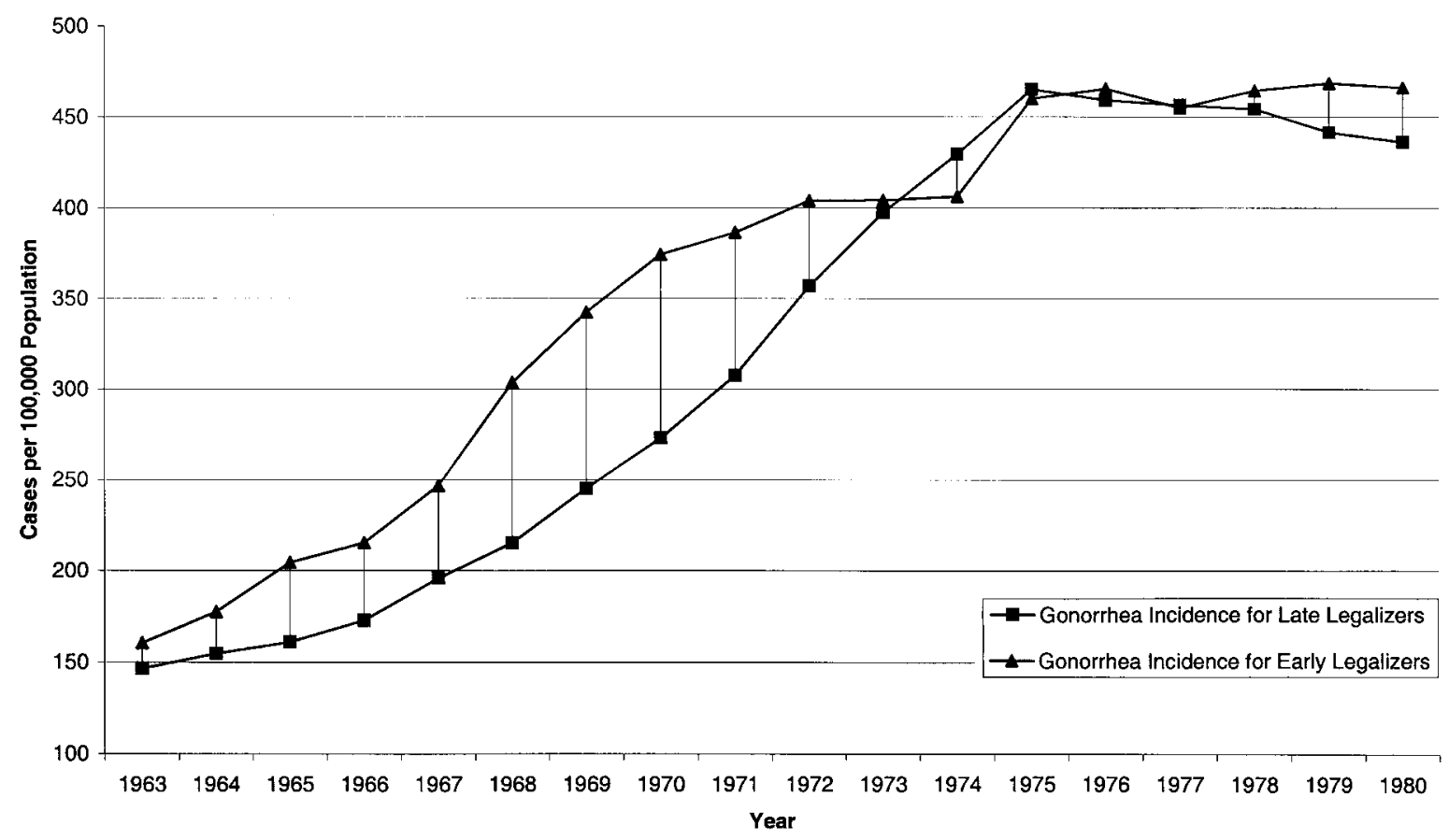

Figure 1. Population-weighted average gonorrhea incidence: 1963-80 


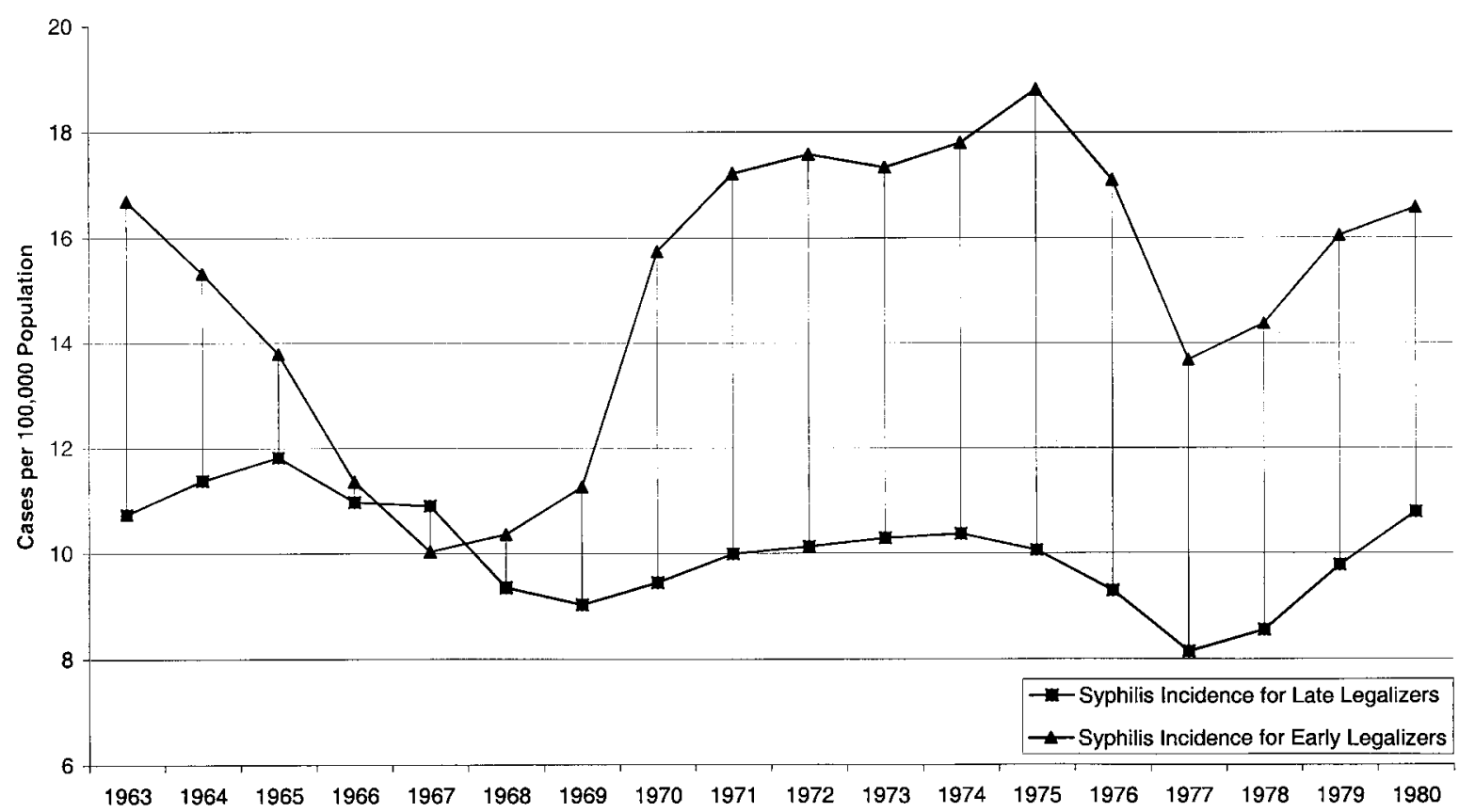
Year

Figure 2. Population-weighted average syphilis incidence: $1963-80$ 
430 / THE JOURNAL OF LEGAL STUdies / VOLUME 32 (2) / JUNE 2003

Table 8. Test for Divergence/Convergence

\begin{tabular}{lcccccccc}
\hline & \multicolumn{3}{c}{ Gonorrhea } & & \multicolumn{3}{c}{ Syphilis } \\
\cline { 2 - 4 } & Total & Male & Female & & Total & Male & Female \\
\hline Early legalizing states & 49.56 & 40.29 & 57.24 & & 3.51 & 5.29 & 1.90 \\
Before 1973 & $(15.03)$ & $(19.12)$ & $(14.51)$ & & $(.87)$ & $(1.12)$ & $(.71)$ \\
Early legalizing states & -6.24 & 7.98 & -21.18 & & 5.27 & 8.95 & 1.72 \\
After 1972 & $(12.58)$ & $(15.99)$ & $(12.14)$ & & $(.72)$ & $(.94)$ & $(.59)$ \\
\hline
\end{tabular}

Note. The dependent variable is the number of individuals per 100,000 who are diagnosed with the STD in year $t$ in state $i . N=918$. All specifications include year and state fixed effects. Standard errors are in parentheses below coefficient estimates.

rates, with the early legalizing states exhibiting relatively higher gonorrhea rates after legalization, but the statistically significant differential disappears once the other states legalize. This result is consistent for rates among both men and women.

The result does not exist for syphilis rates. While we do indeed find relatively higher syphilis rates among the early legalizing states before Roe v. Wade, this significantly higher rate does not disappear after the 1973 decision. We offer two partial explanations for this unexpected result. First, as discussed earlier, the importance of homosexual infections for syphilis weakens the predictive power of our theoretical argument for that disease. As our results indicate, the case for convergence is much weaker for male syphilis rates (in which the post-Roe differential among early legalizing states is especially large) than for female rates (although convergence is still rejected among women too). Potentially, we are detecting some systematic change in male homosexual behavior that confounds our estimate of the abortion effect.

Second, while both gonorrhea and syphilis can be cured with penicillin, syphilis is still contagious for a significant period after treatment, whereas gonorrhea is not contagious after treatment. This lingering effect of syphilis could generate the ongoing differential we observe, as the relatively large pool of diagnosed (and presumably treated) but still contagious individuals with syphilis in the early legalizing states continue to spread the disease through their sexual activities.

\section{CONCLUSION}

The legalization of abortion in the United States led to many changes socially, economically, and medically. While much recent attention has 
focused on its effect with respect to the reduction in unwanted pregnancies, there has been little work that examines the consequences of the increase in sexual activity that likely followed legalization.

We investigate the natural quasi experiment provided by state abortion legalization laws to determine the effect of changing the expected costs of sexual activity on the incidence of sexually transmitted diseases. Changes in abortion laws present a double quasi experiment since a number of states legalized abortion in various years prior to the national legalization that came with Roe $v$. Wade in 1973. Legalizing abortion provided extra incentives to engage in risky sexual activity.

Legalization led to a lowering of the cost of abortions, and this has a qualitatively and quantitatively important effect on STD rates. Our regression results show that abortion legalization led to an increase of sexually transmitted diseases; this result is robust to a wide range of time periods and covariates and is constant across the sexes. The point estimates indicate that legalization caused an increase in the gonorrhea and syphilis rates potentially as large as 25 percent.

In addition to providing further evidence that sexual behavior responds to economic incentives, the results provide an insight into the epidemiology of gonorrhea and syphilis specifically and, perhaps, STDs in general. Our results attribute a large increase in gonorrhea and syphilis rates to changing sexual behavior, which was induced by abortion law changes. This increase resulted in additional expenditures for the treatment of gonorrhea and syphilis on the order of $\$ 300$ million per year. ${ }^{33}$ If a similar abortion effect exists for other STDs, which we could not examine because of data limitations, additional treatment expenditures might amount to more than $\$ 4$ billion annually. ${ }^{34}$

What is clear, however, is that the CDC and medical authorities in general have not considered this abortion effect on STD infection rates, nor have they considered that changes in institutions can cause changes in the relative prices faced by individuals. Instead, the medical community tends to attribute the changes in STD rates to fluctuating social mores, changing demographics, and changing diagnosis patterns. ${ }^{35}$ As indicated by our results, ignoring the effects of changing incentives pre-

33. The Institute of Medicine (1997) estimated that $\$ 1.1$ billion was spent in 1994 to treat gonorrhea infections and that an additional \$106 million went for syphilis treatments. We estimated the abortion effect as accounting for roughly one-quarter of total incidence.

34. The Institute of Medicine (1997) estimated that $\$ 17$ billion was spent on the treatment of all sexually transmitted diseases in 1994.

35. See, for example, Mascola et al. (1983). 
cludes an accurate understanding and modeling of this epidemiological phenomenon.

\section{REFERENCES}

Akerlof, George A., Janet L. Yellen, and Michael L. Katz. 1996. An Analysis of Out-of-Wedlock Childbearing in the United States. Quarterly Journal of Economics 111:277-317.

Angrist, Joshua D., and William N. Evans. 1999. Schooling and Labor Market Consequences of the 1970 State Abortion Reforms. Research in Labor Economics 18:75-113.

Centers for Disease Control. 2000. Sexually Transmitted Disease: Surveillance 1999. Atlanta, Ga.: Centers for Disease Control and Prevention. http:// www.cdc.gov/nchstp/dstd/Stats_Trends/1999SurvRpt.htm.

Donohue, John J. III, and Steven D. Levitt. 2001. The Impact of Legalized Abortion on Crime. Quarterly Journal of Economics 116:379-420.

Edlund, Lena, and Rohini Pande. 2002. Why Have Women Become Left-Wing? The Political Gender Gap and the Decline in Marriage. Quarterly Journal of Economics 117:917-61.

Fortenberry, J. Dennis. 1997. Health Care Seeking Behaviors Related to Sexually Transmitted Diseases among Adolescents. American Journal of Public Health 87:417-20.

Fox, Kimberley K., William L. Whittington, William C. Levine, John S. Moran, Akbar A. Zaidi, and Allyn K. Nakashima. 1998. Gonorrhea in the United States, 1981-1996: Demographic and Geographic Trends. Sexually Transmitted Diseases 25:386-93.

Gayle, Helene D., and George W. Counts. 2001. Syphilis Elimination: A Unique Time in History. Journal of the American Medical Women's Association 56: 2-3.

Goldin, Claudia, and Lawrence Katz. 2002. The Power of the Pill: Oral Contraceptives and Women's Career and Marriage Decisions. Journal of Political Economy 110:730-70.

Gruber, Jonathan, Phillip Levine, and Douglas Staiger. 1999. Abortion Legalization and Child Living Circumstances: Who Is the "Marginal Child?" Quarterly Journal of Economics 114:263-91.

Hamers, F. F., T. A. Peterman, A. A. Zaidi, R. L. Ransom, J. E. Wroten, and J. J. Witte. 1995. Syphilis and Gonorrhea in Miami: Similar Clustering, Different Trends. American Journal of Public Health 85:1104-08.

Hardy, Janet B., and Laurie S. Zabin. 1991. Adolescent Pregnancy in an Urban Environment: Issues, Programs, and Evaluation. Washington, D.C.: Urban Institute Press.

Institute of Medicine. Committee on Prevention and Control of Sexually Trans- 
mitted Diseases. 1997. The Hidden Epidemic: Confronting Sexually Transmitted Diseases. Washington, D.C.: National Academy Press.

Joyce, Ted. Forthcoming. Did Legalized Abortion Lower Crime? Journal of Human Resources.

Kremer, Michael. 1996. Integrating Behavioral Choice into Epidemiological Models of AIDS. Quarterly Journal of Economics 111:549-73.

Levine, Phillip B. 2000. The Sexual Activity and Birth Control Use of American Teenagers. Working Paper No. w7601, National Bureau of Economic Research, Cambridge, Mass.

Levine, Phillip B., and Douglas Staiger. 2002. Abortion as Insurance. Working Paper No. 8813, National Bureau of Economic Research, Cambridge, Mass.

Levine, Phillip B., Douglas Staiger, Thomas J. Kane, and David J. Zimmerman. 1999. Roe v. Wade and American Fertility. American Journal of Public Health 89:199-203.

Lott, John R., Jr., and John E. Whitley. 2001. Abortion and Crime: Unwanted Children and Out-of-Wedlock Births. Law and Economics Research Paper No. 254, Yale University, New Haven, Conn.

Mascola, Laurene, Willard Cates, Jr., Gladys H. Reynolds, Joseph H. Blount, and William L. Albritton. 1983. Gonorrhea and Salpingitis among American Teenagers, 1960-1981. Morbidity and Mortality Weekly Report: Surveillance Summaries 32(3ss): 25ss-30ss.

Moffitt, Robert A. 1998. The Effect of Welfare on Marriage and the Family. In Welfare, the Family, and Reproductive Behavior, edited by Robert Moffitt. Washington, D.C.: National Academy Press.

Posner, Richard A. 1992. Sex and Reason. Cambridge, Mass.: Harvard University Press.

Shrier, Lydia A., Sion K. Harris, M. Sternberg, and William R. Beardslee. 2001. Associations of Depression, Self-Esteem, and Substance Use with Sexual Risk in Adolescents. Preventive Medicine 33:179-89.

Turner, Charles F., Susan M. Rogers, Heather G. Miller, William C. Miller, James N. Gribble, James R. Chromy, Peter A. Leone, Phillip C. Cooley, Thomas C. Quinn, and Jonathan M. Zenilman. 2002. Untreated Gonococcal and Chlamydial Infection in a Probability Sample of Adults. Journal of the American Medical Association 287:726-33.

U.S. Census Bureau. 1963-80. Statistical Abstract of the United States. Washington, D.C.: Government Printing Office. 